\title{
ESTIMULOS QUE FAVORECEM O TREINAMENTO EM LABORATORIO DE ENFERMAGEM: OPINIÃO DE PROFESSORES E ALUNOS
}

\author{
Maria Romana Friedlander* \\ Maria Teresa Cicero Lagand ** \\ Carla Silveira $* * *$ \\ Monalisa A. Szobo ***
}

FRIEDLANDER, M.R.; LAGANA, M.T.C.; SILVEIRA, C.; SZOBO, M.A. Estimulos que favorecem o treinamento em laboratório de enfermagem: opinião de professores e alunos. Rev. Esc. Enf. USP, São Paulo, 24(1):41-65, abr. 1990.

Estudo da opinião de 5 docentes e 48 esutdantes em relação aos fatores que podem estimular ou desestimular o comparecimento espontaneo dos estudantes para treinamento das habilidades psicomotoras no laboratório de enfermagem. Os resultados mostraram respostas positivas e negativas apontadas por professores e alunos na valorização do treinamento no laboratório de enfermagem.

UNITERMOS: Ensino de enfermagem. .Treinamento em laboratório.

\section{INTRODUÇÃO}

A despeito da utilização planejada do Laboratório de Enfermagem (L.E.) como recurso instrucional durante o desenvolvimento da disciplina Fundamentos de Enfermagem I do Curso de Graduação, desde 1983, para promover um reforço de aprendizagem, os estudantes têm a possibilidade de 0 freqüentar sem a obrigatoriedade da presença do professor ou de cumprimento de horário, como atividade de livre opção. Esta atividade já foi descrita em 1984 por FRIEDLANDER et alli.

Essa frequência espontânea do estudante ao L.E. tem sido registrada com a intenção de se conhecer de forma mais ampla e profunda essa atividade cujos dados podem gerar subsidios para uma futura ampliação das perspectivas da utilização do L.E.

Acredita-se que, como em qualquer comportamento humano, existam fatores que podem estimular ou desestimular o comportamento em uma certa direção e com um certo rítmo. Uma vez que não houve alteraçōes

- Enfermeira. Professor Assistente Doutor do Departamento de Enfermagem Médico-Cirúrgica da Escola de Enfermagem da Universidade de Săo Paulo.

** Enfermeira Professor Assistente do Departamento de Entermagem Médico-Cirúrgica da Escola de Enfermagem da Universidade de São Paulo.

*** Alunas-Monitoras de Fundamentos de Enfermagem I da Escola de Enfermagem da Universidade de Stao Paulo. 
na abordagem da disciplina como um todo e os professsores, em maioria, mantiveram-se os mesmos durante os últimos cinco anos, ficam várias questões. Em toda as turmas a frequência espontânea média ao L.E. dos estudantes é a mesma? Para desenvolver os mesmos tipos de habilidades? Mantem-se constante durante todo o semestre letivo no qual se desenvolve a disciplina? Se há alterações, quais os fatores que determinam essas alteraçōes?

As respostas a essas questōes podem tornar possivel a tcmada de medidas no intuito de desenvolver ou aprimorar o laboratório como recurso de ensino apropriando-o para o desenvolvimento das habilidades eminentemente psicomotoras dos estudantes de enfermagem.

Sabe-se que cada estudante tem características próprias e individuais que nem sempre são atendidas com o ensino de massa. O treinamento planejado pelos professores em determinado horário e com a utilização de determinadas estratégias não atende a alguns tipos de estudantes que aprendem segundo estilos diferentes. Assim o estudante deve contar com recursos instrucionais apropriados para atender às suas características próprias e o laboratório de enfermagem pode ser um valioso instrumento.

Num primeiro momento destas preocupações procurou-se fazer um levantamento da literatura relacionada à motivação e à estimulação do estudante em sala de aula cujo resumo encontra-se publicada por FRIEDLANDER et alli (1989). Não se encontrou nada relacionado especificamente às habilidades psicomotoras de enfermagem mas alguns conhecimentos e subsídios foram captados.

Pos

Posteriormente iniciou-se a elaboração do presente trabalho com os seguintes objetivos:

1) Identificar o número de comparecimento espontâneos dos estudantes de 1985, 1986 e 1987 ao Laboratório de Enfermagem para treinamento das técnicas constantes do conteúdo programático de Fundamentos de Enfermagem I, durante o periodo letivo daquela disciplina.

2) Verificar o período do semestre letivo em que houve maior número de comparecimentos desses estudantes ao L.E.

3) Relacionar as técnicas treinadas por esses estudantes no L.E. nesse período.

4) Identificar os fatores que estimularam e os que desestimularam a frequência espontânea ao L.E. na opinião dos docentes da disciplina.

5) Identificar os fatores que estimularam a frequência espontânea ao L.E. na opinião dos próprios alunos.

\section{METODOLOGIA}

Este trabalho foi realizado na Escola de Enfermagem da Universidade de São Paulo em duas etapas. A primeira etapa visou analisar os 
dados registrados do comparecimento dos estudantes da disciplina Fundamentos de Enfermagem I nos anos de 1985, 1986 e 1987, ao Laboratório de Enfermagem, fora dos horários planejados pela disciplina. Analisou-se apenas os dados relacionados aos alunos que freqüentaram a referida disciplina até ao final da mesma. O instrumento usado para o registro dessa freqüência (Anexo I) permitiu que cada estudante anotasse a data e a técnica treinada.

A segunda etapa visou coletar a opinião desses estudantes e dos docentes da disciplina em questão frente às condições e aos fatores que estimularam ou desestimularam o comparecimento espontâneo dos alunos para treinamento no L.E. Construiu-se um formulário (Anexo II) que, além de colher informações que identificassem o respondente, abria espaço para que fosse dada a opinião livre sobre as condições estimulantes e desestimulantes, bem como a opinião com base numa listagem (Anexos III e IV) pré-elaborada das condiçōes descritas na literatura estudada (FRIEDLANDER et alli 1989).

A aplicação do instrumento acima descrito foi realizada pelas autoras do presente trabalho pedindo ao respondente que desse sua opinião sobre os assuntos em questão, primeiro sem as listas e, por último, com base nas listas pré-claboradas. Dessa forma obtivemos duas respostas sobre as condições estimulantes e duas respostas sobre as condições desestimulantes, de rada respondente, sendo que uma de cada item era aberta e a outra fechada.

O formulário foi aplicado a todas as docentes da disciplina em questão que participaram do desenvolvimento da mesma nos anos estudados, num total de 5. Foi também aplicado a 16 alunos de cada ano totalizando 48 estudantes. Para a seleção dos estudantes respondentes exigiu-se que os mesmos tivessem frequientado até ao final aquela disciplina na Escola de Enfermagem da USP.

Para se formar o grupo de 16 de cada ano escolheram-se 4 alunos que não tivessem freqüentado o L.E., 4 que tivessem freqüentado com assiduidade baixa (de uma a três vezes), 4 que tivessem freqüentado com assiduidade média (de quatro a 7 vezes) e 4 com assiduidade alta (mais de 7 vezes). total.

A amostra de 48 estudantes representa cerca de $25 \%$ da população

\section{APRESENTAÇÃO E DISCUSSÃO DOS RESULTADOS}

Freqüentaram a referida disciplina um total de 188 estudantes,

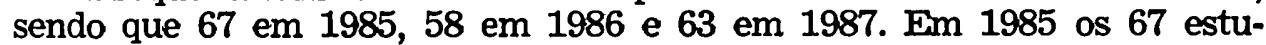
dantes foram ao laboratório 526 vezes, ou seja, 7,8 comparecimentos em média por aluno. Em 1986 e 1987, respectivamente, a média por aluno foi 2,9 e 3,2 ou seja, menos da metade que em 1985.

O gráfico 1 e a Tabela I mostram a distribuição desses comparecimentos de Enfermagem I. Além de deixar clara a diferença no número de comparecimentos dos estudantes de 1985 quando comparados 
GRAFICO 1 - Número de comparecimentos espontâneos dos estudantes ao L.F. pelas quinzenas do 19 semestre letivo dos anos de 1985, 1986 e 1987. São Paulo.

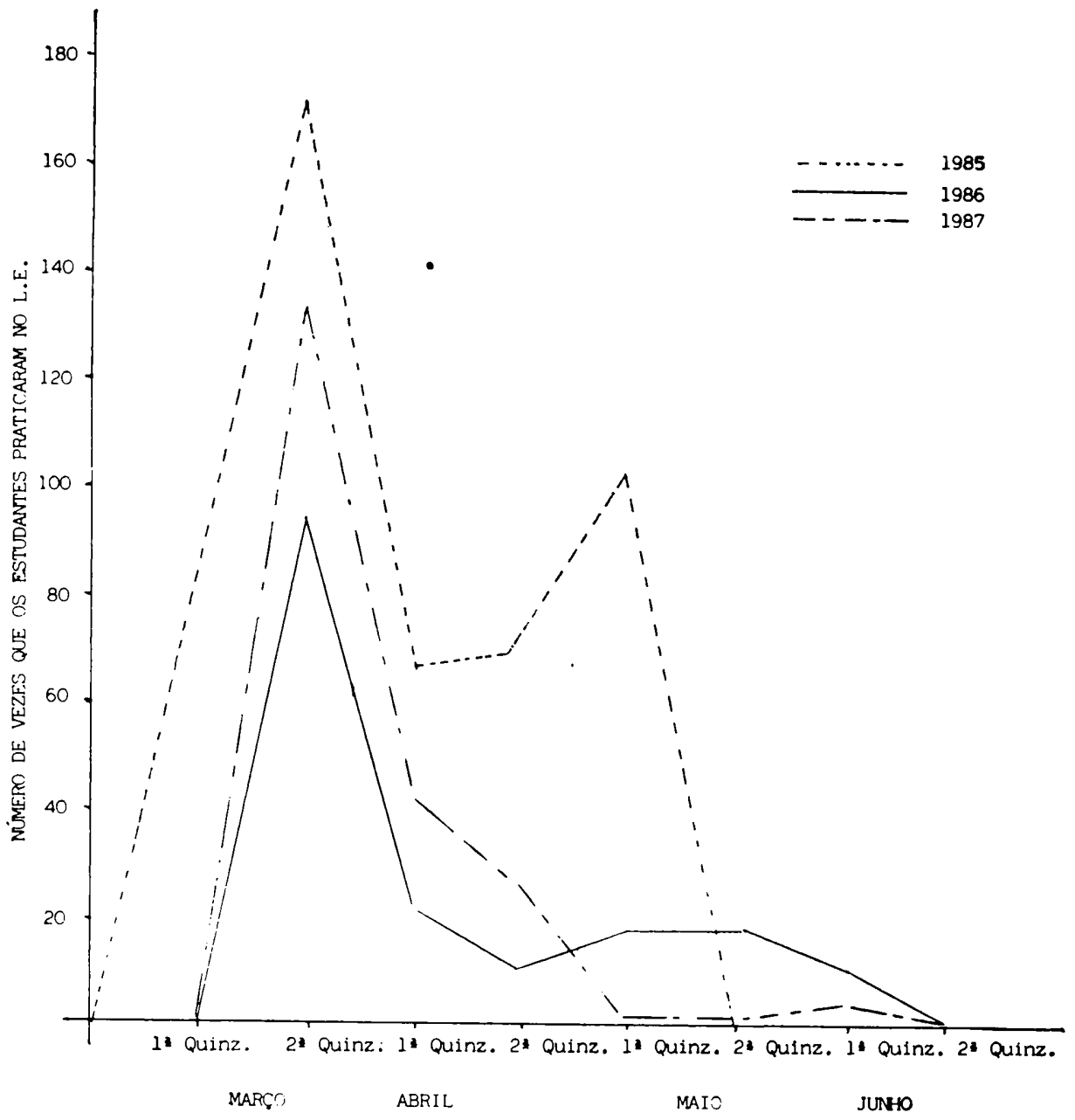

com os de 1986 e 1987, o gráfico 1 e a Tabela I também chamam a atenção para o fato do comparecimento não ser estável em todo o semestre. Nas três turmas, na $2^{*}$ quinzena de março, o número de com-parecimentos apresentou um pico significativo e, após, houve uma diminuição quase constante até junho. Nas turmas de 85 e 86 aparece um novo recrudescimento no número de comparecimentos, em maio, quando as estudantes estão iniciando o estágio clínico. Em 1987 esse segundo aumento não apareceu na mesma época pois houve paralização de aulas durante o mês de maio; os estágios começaram em junho.

O primeiro grande pico, em março, talvez se deva ao fato dos estudantes estarem iniciando seu contato com as técnicas e a curiosidade e o entusiasmo por novas atividades costuma atuar como agente motivador. 
T A B E L A I

NOMERO DE COMPARECIMENTOS ESPONTANEOS DOS ESTUDANTES

AO LABORATORIO DE ENFERMAGEM PELAS QUINZENAS DO $10^{\circ}$ SEMESTRE LETIVO DE 1985, 1986 e 1987. SARO PAULO.

\begin{tabular}{|c|c|c|c|c|}
\hline \multirow{2}{*}{ Quilnzenas } & \multicolumn{4}{|c|}{ Anos } \\
\hline & 1985 & 1986 & 1987 & Tottal \\
\hline $\begin{array}{llll}\text { de } & 01 & \text { a } & 15 / 03 \\
\text { de } & 15 & \text { a } & 91 / 03 \\
\text { de } & 01 & \text { a } & 15 / 04 \\
\text { de } & 15 & \text { a } & 30 / 04 \\
\text { de } & 01 & \text { a } & 15 / 05 \\
\text { de } & 15 & \text { a } & 31 / 05 \\
\text { de } & 01 & \text { a } & 16 / 06 \\
\text { de } & 15 & \text { a } & 30 / 06\end{array}$ & $\begin{array}{r}93 \\
170 \\
66 \\
69 \\
102 \\
26 \\
-\end{array}$ & $\begin{array}{l}- \\
93 \\
21 \\
10 \\
17 \\
17 \\
10 \\
-\end{array}$ & $\begin{array}{r}-\overline{132} \\
42 \\
27 \\
- \\
4\end{array}$ & $\begin{array}{r}93 \\
395 \\
129 \\
106 \\
119 \\
43 \\
14 \\
0\end{array}$ \\
\hline Total & 526 & 168 & 205 & 899 \\
\hline
\end{tabular}

Quanto às técnicas treinadas, por essas turmas, no periodo em questão, podem ser observadas na Tabela II.

T A B E L A II

NOMERO DE TREINAMENTOS, REALIZADOS PELOS ESTUDANTES, DE CADA UMA DAS TECNICAS DE ENFERMAGEM CONTIDAS NO CONTEODO DA DISCIPLINA FUNDAMENTOS DE ENFERMAGEM, NOS ANOS 1985, 1986 e 1987. SAX PAULO.

\begin{tabular}{|c|c|c|c|c|}
\hline \multirow{2}{*}{ Técnicas } & \multicolumn{4}{|c|}{ Anos } \\
\hline & 1985 & 1986 & 1987 & Tottal \\
\hline 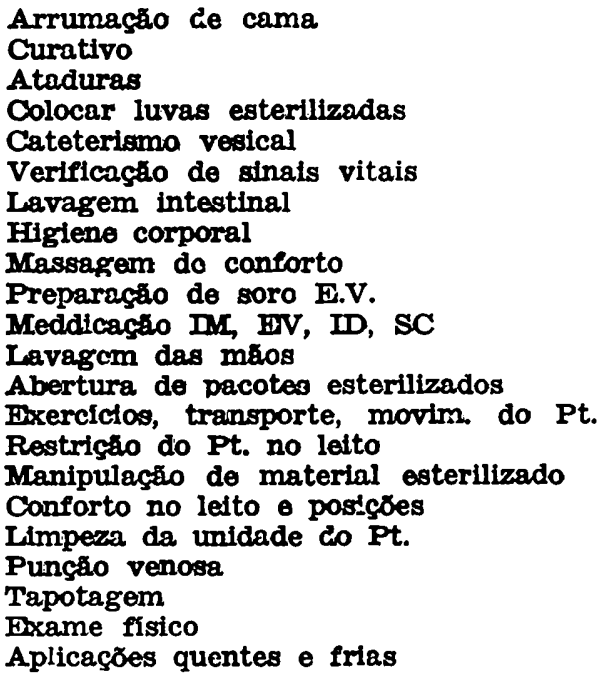 & $\begin{array}{r}110 \\
71 \\
62 \\
51 \\
89 \\
75 \\
55 \\
5 \\
9 \\
38 \\
18 \\
29 \\
17 \\
15 \\
39 \\
9 \\
20 \\
4 \\
2 \\
1\end{array}$ & $\begin{array}{r}95 \\
15 \\
7 \\
10 \\
2 \\
14 \\
3 \\
2 \\
12 \\
20 \\
- \\
6 \\
2 \\
8 \\
3 \\
- \\
- \\
-\end{array}$ & $\begin{array}{r}141 \\
103 \\
116 \\
109 \\
16 \\
10 \\
13 \\
88 \\
40 \\
1 \\
-43 \\
5 \\
- \\
2 \\
8 \\
1 \\
1 \\
\end{array}$ & $\begin{array}{r}346 \\
189 \\
185 \\
170 \\
107 \\
99 \\
70 \\
95 \\
61 \\
38 \\
39 \\
29 \\
43 \\
17 \\
17 \\
39 \\
19 \\
11 \\
20 \\
5 \\
3 \\
1\end{array}$ \\
\hline Totais & 7719 & 199 & 697 & 1615 \\
\hline
\end{tabular}


Nesta última Tabela verifica-se que as técnicas "Arrumação de cama", "Curativo", "Ataduras", "Colocação de luvas esterilizadas" e "Cateterismo vesical" são as técnicas mais procuradas para serem treinadas. Em 1984, FRIEDLANDER et alli relataram um levantamento com objetivos semelhantes realizado numa população semelhante (da mesma instituição, cujo ensino foi ministrado com abordagem semelhante e por um grupo de professores parecido) onde também foi verificado que "Arrumação de cama", "Colocação de luvas esterilizadas" e "Curativo" eram as técnicas preferidas e nas quais os estudantes aplicavam mais tempo de treino.

Nesse artigo as autoras levantaram várias hipóteses para explicar a preferência. Agora sugere-se que outros estudos sejam realizados sobre as caracteristicas da habilidade manual e das dificuldades de aprendizagem psicomotora relacionadas com essas técnicas, bem como da relação da abordagem da disciplina como um todo e essas técnicas.

Na Tabela II nota-se, ainda, que em 1986 o número de técnicas número de comparecimentos dos estudantes ao L.E. (Tabela I).

Com a intenção de tentar uma explicação para essas diferenças entre as turmas foi ouvida a opinião dos docentes que participaram no ensino dessas técnicas nos três anos em questão sobre os possíveis fatores que estimulam ou desestimulam os estudantes. Ouviram-se um total de 5 professores e 48 estudantes a quatro questões:

1) Condiçōes que estimulam o aluno a freqüentar o L.E. espontaneamente (resposta aberta).

2) A mesma questão 1 mas com a resposta orientada pela Lista 1 .

3) Condições que desestimulam o estudante a freqüentar o L.E. de forma expontânea (resposta aberta).

4) A mesma questão 3 mas com resposta orientada pela Lista 2.

Os resultados encontrados para a questão $n^{\circ} 1$ podem ser observados na Tabela III. Analisando-se essa tabela verifica-se que os estudantes concordam com a bibliografia (AUSUBEL et alii 1980 e SLAVIN, 1984) quando dizem uue a maior responsabilidade frente à motivação está no próprio aluno. Os íters 19 e 20 consideram um grande número de respostas, ou seja, 39,6\% dos estudantes apontaram "a vontade de saber mais do estudante" e 47,9\% indicaram "a necessidade de sentir-se seguro frente ao paciente e à nova situação do estágio" como condições estimulantes para o comparecimento espontâneo ao L.E.

Com $15 \%$ ou mais de indicações por alunos ainda apareceram como condições estimulantes "número de monitores no L.E. suficiente para atender à demanda de alunos" e "provas práticas na disciplina".

Das 114 respostas à questão aberta sobre as condiçōes estimulantes, $61(53,5 \%)$ estão relacionadas ao aluno na opinião dos próprios estudantes, enquanto $26(22,8 \%)$ relacionam-se ao professor ou monitor, 3 


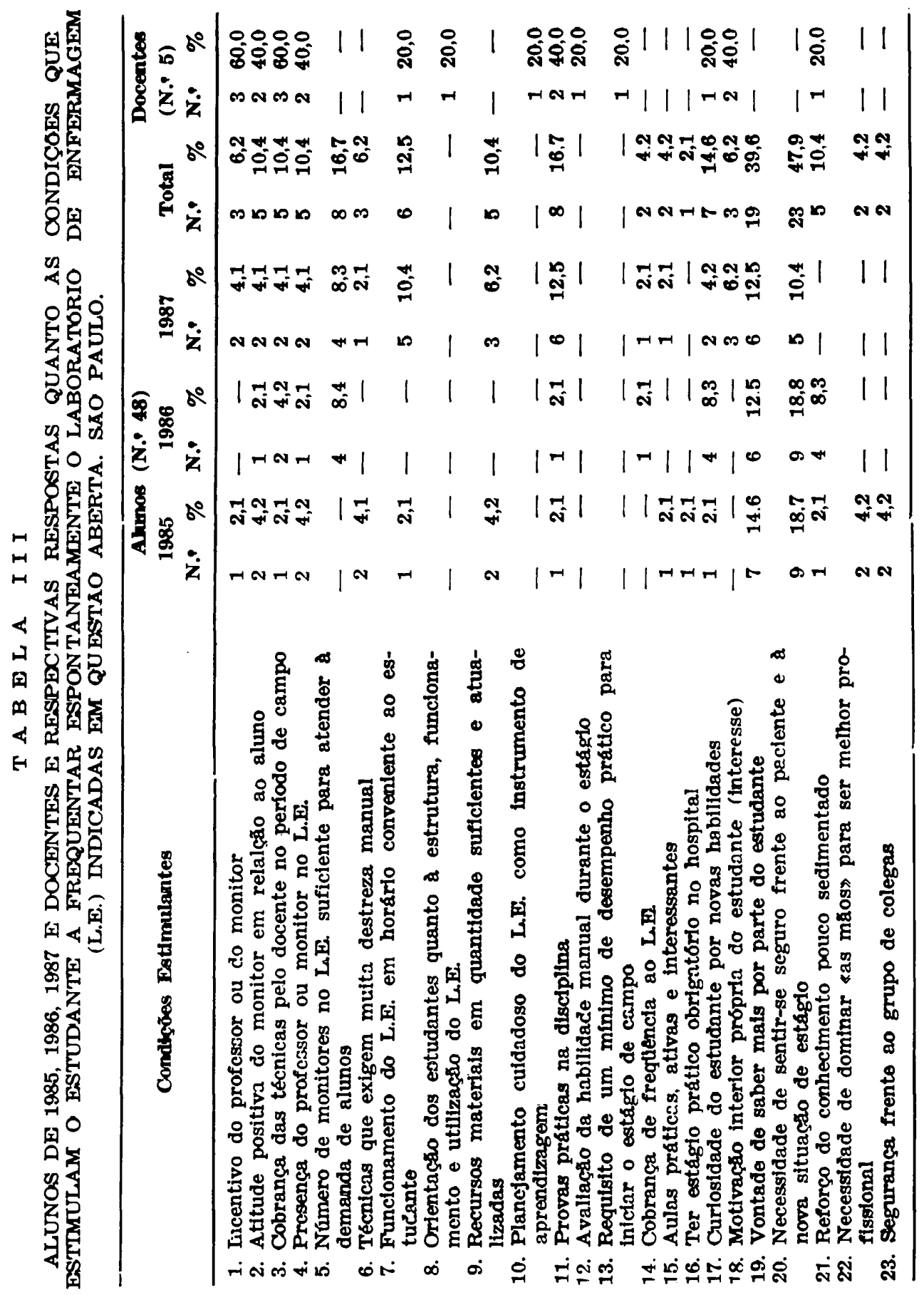


$(2,6 \%)$ às técnicas, $14(12,3 \%)$ ao laboratório de enfermagem e 13 $(11,4 \%)$ às condiçōes da disciplina.

Em relação à opinião dos docentes verifica-se que, ao contrário, o incentivo parece ser da responsabilidade do professor ou monitor uma vez que, das 21 respostas, $10(47,7 \%)$ relacionam-se ao professor ou monitor, enquanto $4(19,0 \%)$ indicam o estudante. No entanto, $40 \%$ ou mais dos docentes apontaram condições como:

- Incentivo do professor ou monitor.

- Atitude positiva do monitor em relação ao estudante. campo.

- Cobrança das técnicas pelo docente no periodo de estágio de

- Presença do professor ou monitor no L.E.

- Provas práticas na disciplina.

- Motivação interior própria do estudante (interesse).

Quando se apresentou a Lista 1 para os docentes e os estudantes responderam à questão $\mathrm{n}^{\circ} 2$, obtiveram-se respostas cujos resultados encontram-se na Tabela $\mathrm{n}^{4}$ IV.

Em relação às respostas dadas pelos estudantes, $30 \%$ ou mais de estudantes apontaram os itens:

- O professor mostra de forma clara e precisa os objetivos do treinamento de cada uma das técnicas. no L.E.

- O professor demonstra entusiasmo pelo treinamento dos alunos

- O professor mostra explicitamente ao estudante aquelas habilidades que ele não executa bem e que deveriam ser melhor treinadas.

- O professor está disponivel quando o estudante precisa de auxilio para treinar no L.E.

- O professor de estágio no campo é exigente e cobra a habilidade.

- A técnica parece complexa durante a aula teórica ou a demonstração.

- A técnica já é conhecida do aluno (viu alguém fazer ou ouviu alguém mencioná-la) antes de começar a disciplina Fundamentos de Enfermagem.

- A técnica já foi necessaria ao aluno (para atender alguém da família ou colega) que não executou por não a conhecer.

- O laboratório conta com a presença do aluno-monitor.

- O laboratório conta com a presença do professor.

- O laboratório conta com material e equipamento suficiente em quantidade e qualidade. 


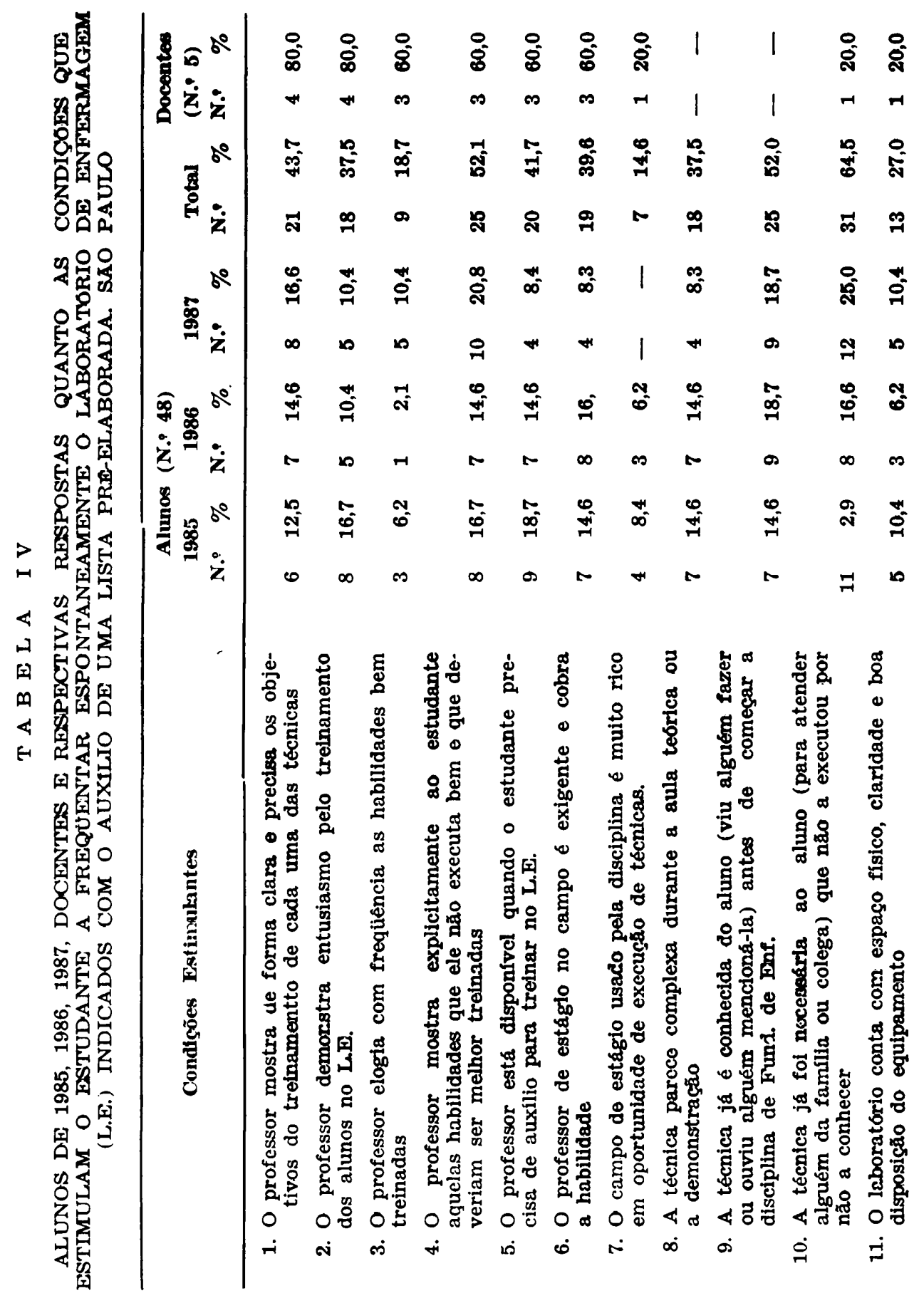




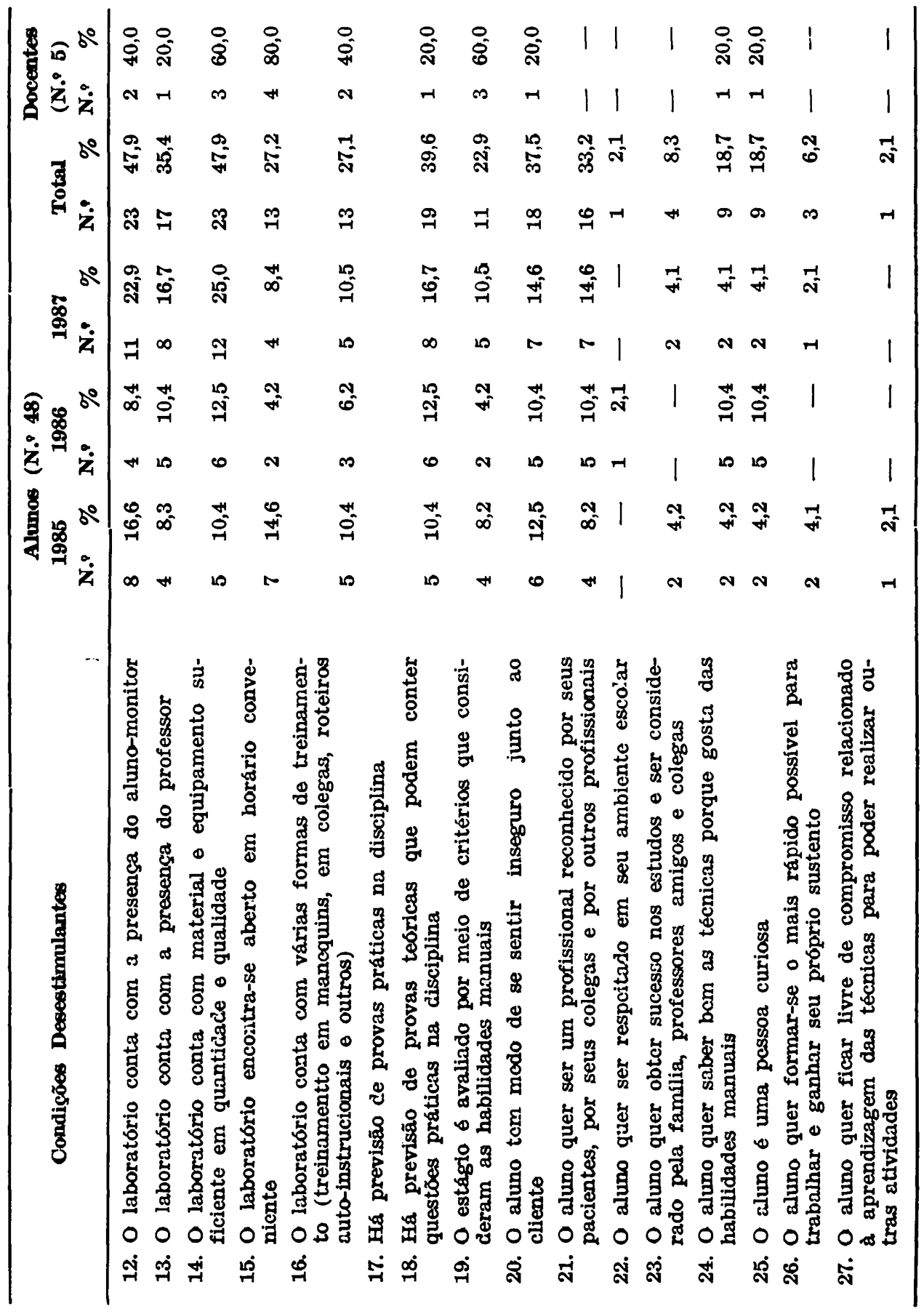


- Há previsão de provas práticas na disciplina.

- Há precisão de provas teóricas que podem conter questões práticas na disciplina.

- $\mathrm{O}$ aluno tem medo de se sentir inseguro junto ao cliente.

- O aluno quer ser um profissional reconhecido por seus pacientes, por seus colegas e por outros profissionais.

Nota-se que apenas dois dos itens mais apontados refere-se ao estudante. Aocontrário do que aconteceu na questão anterior, das 416 respostas $112(26,9 \%)$ referem-se ao professor, enquanto $102(24,5 \%)$ apontam o laboratório de enfermagem, $74(17,8 \%)$ referem-se às técnicas ,66 (15,9\%) indicam condições da disciplina e $622(14,9 \%)$ o aluno.

Os docentes deram 45 respostas e destas, $20(44,4 \%)$ referem-se ao professor como responsável pelo estímulo do estudante, enquanto apenas $2(4,4 \%)$ relacionam-se ao aluno.

Dentro de todas as respostas dadas pelos docentes os itens abaixo foram indicados por $40 \%$ ou mais de docentes:

- O professor mostra de forma clara e precisa os objetivos do treinamento de cada uma das técnicas. no L.E.

- O professor demonstra entusiasmo pelo treinamento dos alunos

- O professor elogia com frequência as habilidades bem treinadas.

- O professor mostra explicitamente ao estudante aquelas habilidades que ele não executa bem e que deveriam ser melhor treinadas.

- O professor está disponivel quando o estudante precisa de auxílio para treinar no L.E.

- O professor de estágio no campo é exigente e cobra habilidade.

- O laboratório conta com a presença do aluno-monitor.

- O laboratório conta com material e equipamento suficiente em quantidade e qualidade.

- O laboratório encontra-se aberto em horário conveniente.

- O laboratório conta com várias formas de treinamento (treinamento em manequins, em colegas, roteiros auto-instrucionais e outros).

- Há previsão de provas práticas na disciplina. habilidades.

- O estágio é avaliado por meio de critérios que consideram as

Nenhum destes itens refere-se ao estudante.

Se considerarmas as condições do L.E. e.da disciplina como responsabilidade do professor no desempenho de seu papel de facilitador e 


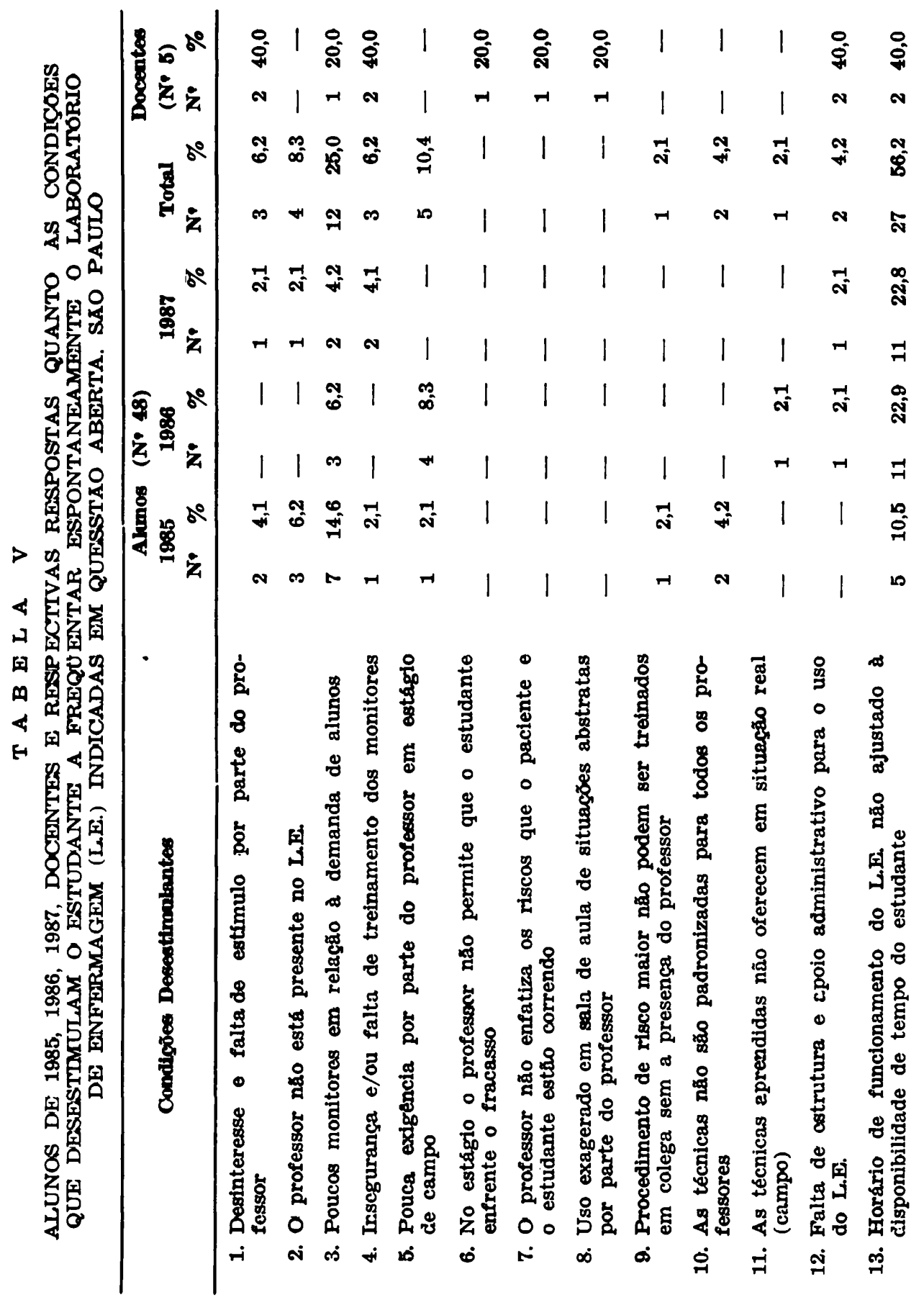




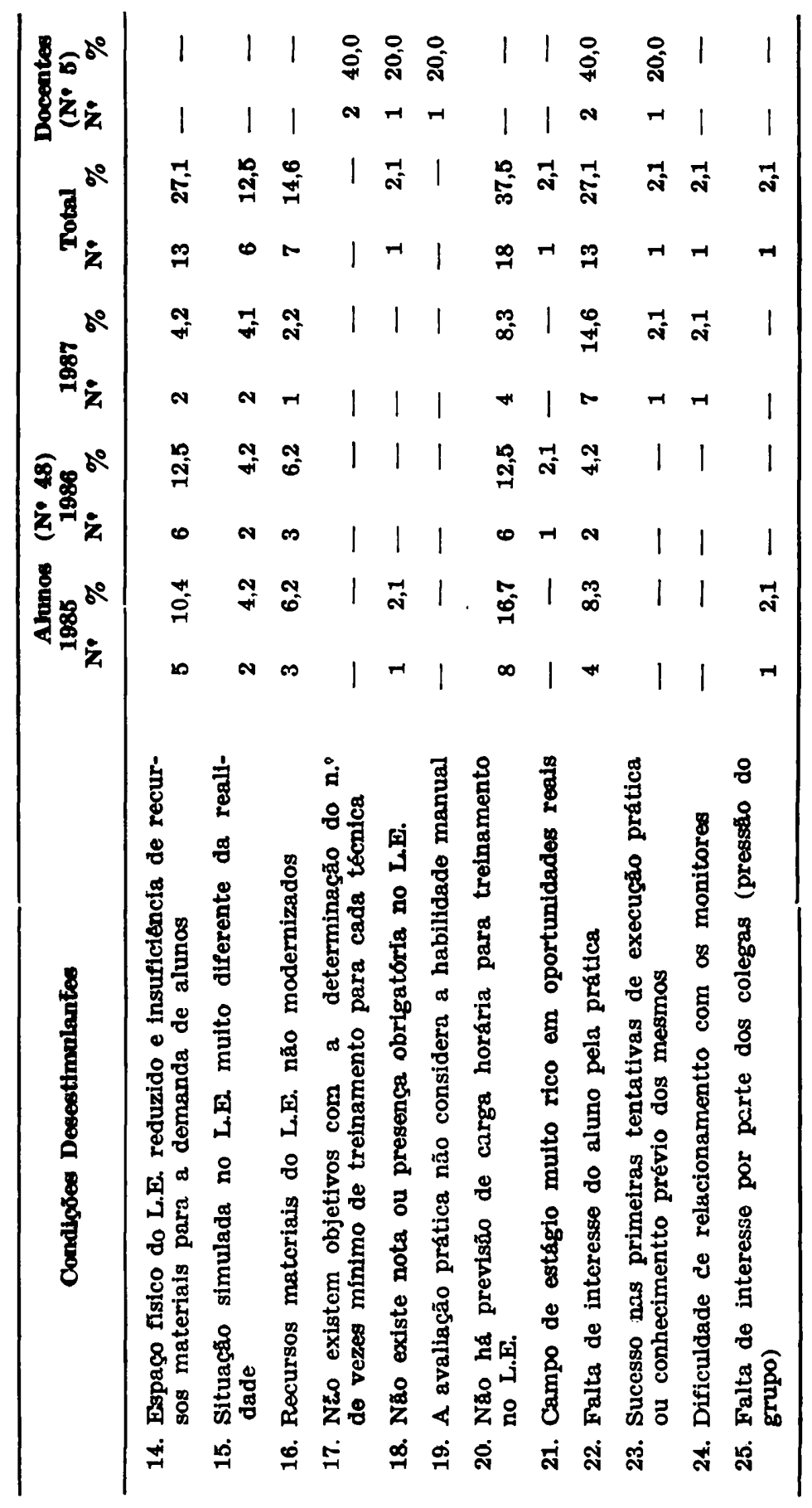


orientador da aprendizagem, evidencia-se com mais clareza que tanto os docentes como os alunos atribuem ao professor maior responsabilidade pela estimulação dos estudantes para frequentarem espontaneamente o laboratório de enfermagem. Fica bastante nítida que a estimulação, como é definida por CAMPOS (1984) e NERICI (1984), é atribuição do professor. Contudo os estudantes demonstram claramente que a motivação é fator determinante no comparecimento espontâneo ao L.E.

Comparando as duas tabelas ( $n^{\circ} \mathrm{WI}$ e IV) verifica-se que os estudantes de 1985 e 1987 foram os que apontaram mais vezes o professor ou o monitor como responsável pelas condições estimulantes. Estes grupos foram os que compareceram espontaneamente ao L.E. Mais vezes para treinamento (Tabela $n^{\circ}$ I e Gráfico $n^{\circ} 1$ ) e os que maior número de respostas ofereceram tanto para a questão aberta (Tabela $n^{\circ}$ III) como para a questâo fechada - com auxílio de lista pré-elaborada - (Tabela $\mathrm{n}^{\circ}$ IV).

O grupo de 1985 também parece ter mais consciência do papel da motivação interior do próprio estudante no estudo espontâneo pois foi o grupo que maior número de vezes indicou condições estimulantes relacionadas ao aluno na questão aberta.

As questões 3 e 4 referem-se às condições que desestimulam os estudantes a comparecerem espontaneamente ao L.E. Os resultados encontrados para a questão 3 (aberta) podem ser vericados na Tabela $\mathrm{n}^{\circ} \mathrm{V}$.

Nessa tabela os estudantes ofereceram um total de 121 respostas. Dessas, $55(48,0 \%)$ referem-se às condições do laboratório de enfermagem, $27(22,3 \%)$ ao professor ou monitor, $20(16,5 \%)$ à disciplina, 15 $(12,4 \%)$ ao estudante e $4(3,3 \%)$ às técnicas.

Do total de estudantes, $15 \%$ ou mais apontaram os itens abaixo como condiçōes que podem desestimular a frequência espontânea do aluno ao L.E.:

- Poucos monitores em relação à demanda de alunos.

- Horário de funcionamento do L.E. não ajustado à disponibilidade de tempo do estudante.

- Espaço físico do L.E. reduzido e insuficiência de recursos materiais para a demanda de alunos. disciplina).

- Falta de interesse do aluno pela prática.

$\mathrm{Na}$ opinião do corpo discente as condições do laboratório de enfermagem parecem arcar com a responsabilidade maior em desestimular o aluno, seguidas de condiçöes relacionadas ao professor ou monitor. Contudo, a falta de motivação interior do aluno, na visão do próprio estudante, é um fator significativo. 
$\mathrm{Na}$ Tabela $\mathrm{n}^{\circ} \mathrm{V}$, no que se relaciona aos docentes, estes ofereceram um total de 19 respostas e destas $8(42,1 \%)$ relacionam-se ao papel do próprio professor. Os itens citados por $40 \%$ ou mais docentes são:

- Desinteresse e falta de estímula por parte do professor.

- Insegurança e/ou falta de treinamento dos monitores.

- Falta de estrutura e apoio administrativo para o uso do LE.

- Horário de funcionamento do L.E. não ajustado à disponibilidade de tempo do estudante.

- Não existem objetivos com a determinação do $n^{\circ}$ de vezes mínimo de treinamento para cada técnica.

- Falta de interessc do aluno pela prática.

Aqui os docentes também concordam com os estudantes com a importância da motivaçãa do aluno para não frequentarem o L.E.

Em se tratando das respostas com o auxílio da lista pré-elaborada (questão 4) os resultados podem ser observados na Tabela $\mathrm{n}^{\circ}$ VI.

$\mathrm{Na}$ presente tabela $15 \%$ ou mais de estudantes apontaram quase todas as condições como desistimulantes. A excessão é feita ao horário de funcionamento do L.E. que apenas 5 estudantes indicaram como condição importante, talvez porque já a haviam mencionado em questões anteriores. Destaca-se como indicação por mais de $30 \%$ de estudantes os itens:

- O professor não valoriza as técnicas que o aluno treinou.

- O professor não tem disponibilidade quando o aluno lhe pede auxilio para treinar no L.E.

- O professor ou monitor transmitem muita ansiedade ao estudante durante o treinamento no L.E.

- As técnicas parecem pouco úteis (ou de uso pouco comum ou de uso remoto) durante a demonstração ou a aula teórica.

- O campo de estágio usado pela disciplina é pobre em oportunidades para a execução das técnicas.

- O laboratório de enfermagem conta com pouco espaço físico, pouca claridade ou com uma disposição de material pouco conveniente.

- O L.E. não conta com a presença do aluno-monitor.

- O L.E. não conta com a presença de um professor.

- O L.E. não conta com equipamento e material suficiente em quantidade e qualidade.

- $O$ aluno já tem experiência anterior na execução das técnicas.

Das 308 respostas oferecidas pelos estudantes, $100(32,5 \%)$ referem-se ao docente, $85(27,6 \%)$ às condições do L.E. e $55(17,9 \%)$ ao próprio aluno. 


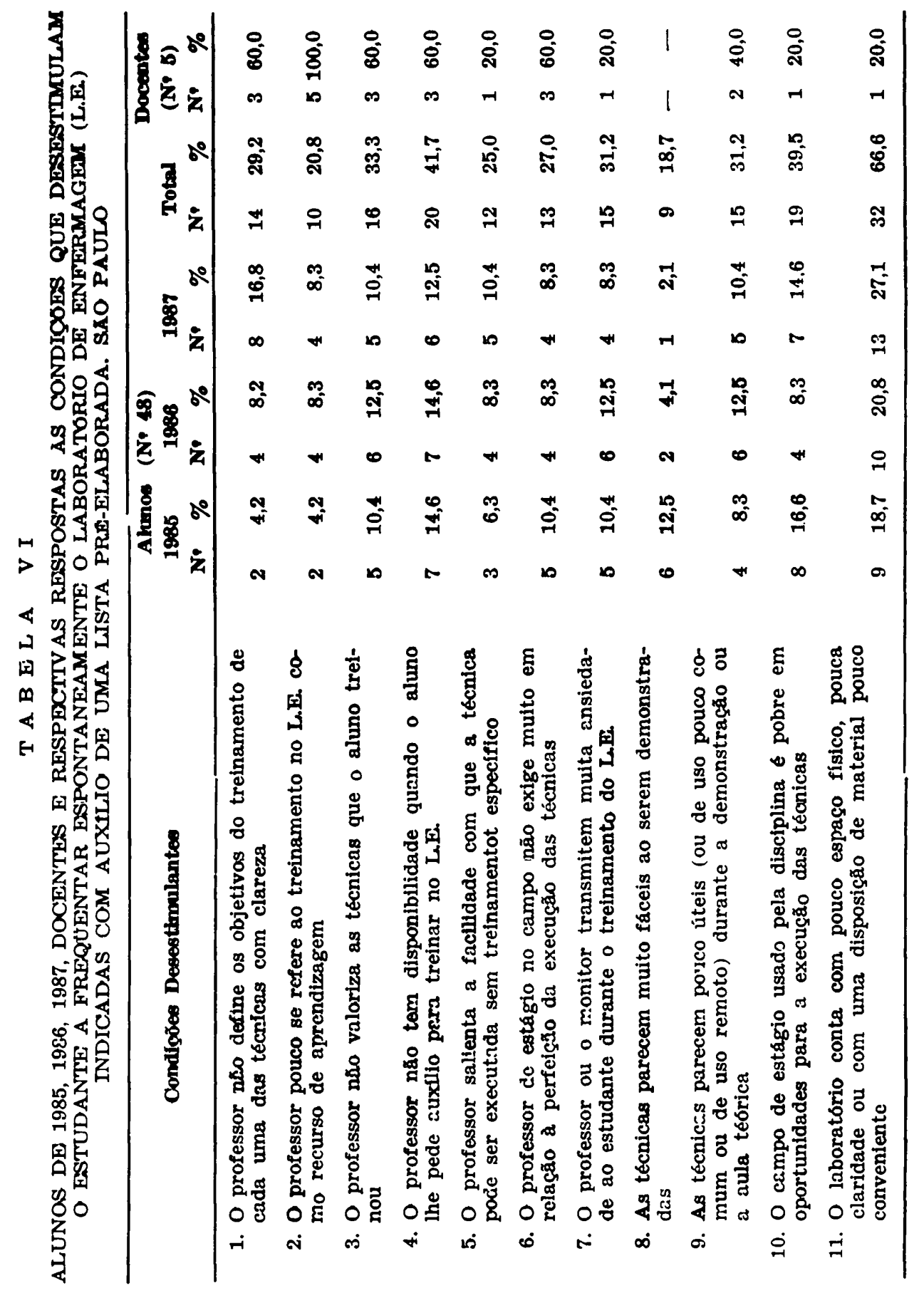




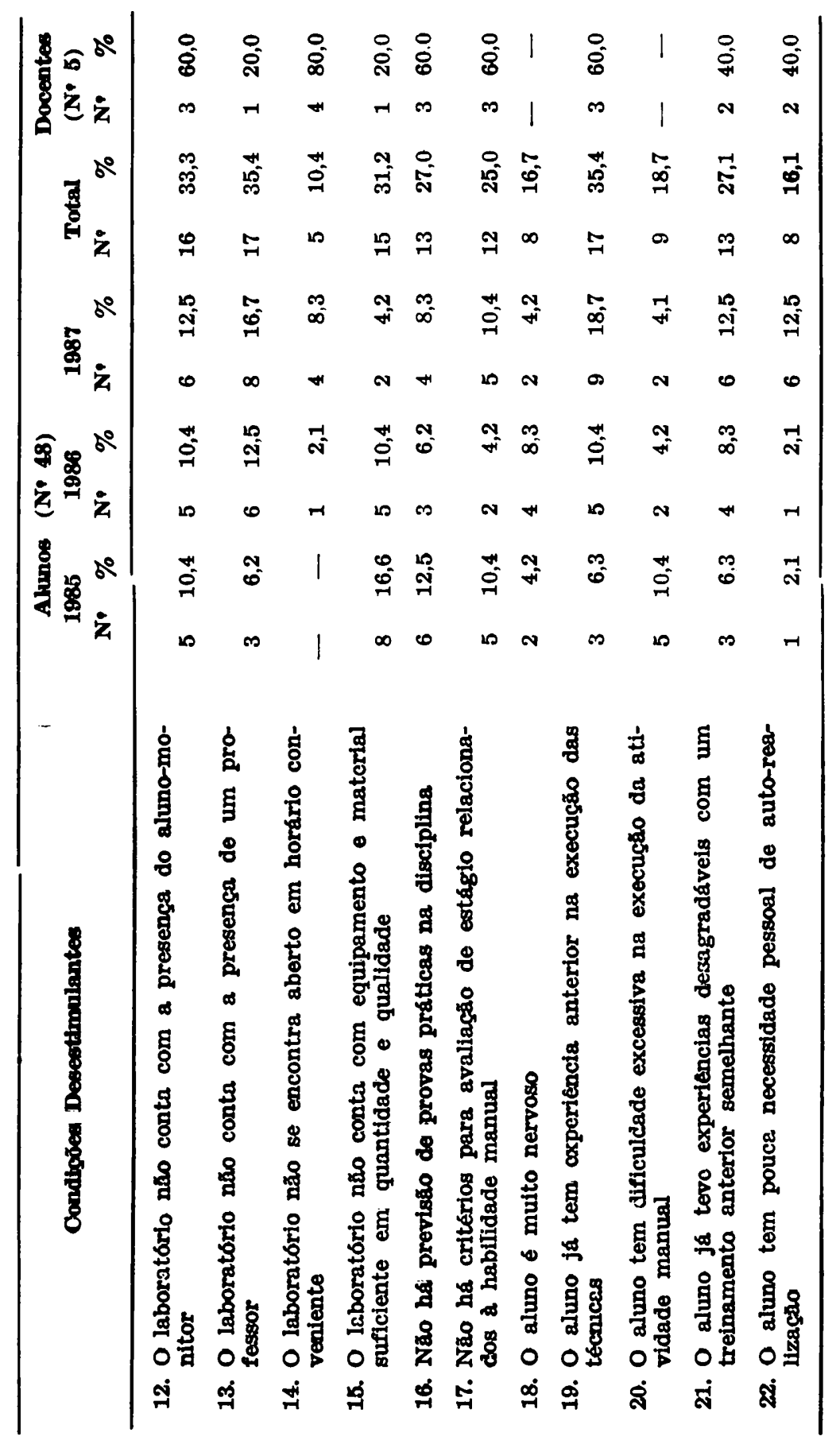


Nesta questão também o grupo de 1987 ofereceu maior número de respostas.

No que diz respeito aos docentes, estes ofereceram um total de 45 respostas e $40 \%$ ou mais de docentes apontaram como condições desestimulantes os seguintes itens:

- O professor não define os objetivos do treinamento de cada uma das técnicas com clareza.

- O professor pouco se refere ao treinamento no L.E. como recurso de aprendizagem.

- O professor não valoriza as técnicas que o aluno treinou.

- O professor não tem disponibilidade quando o aluno lhe pede auxilio para treinar no L.E.

- O professor de estágio no campo não exige muito em relação à perfeição da execução das técnicas.

- As técnicas parecem pouco úteis (ou de uso pouco comum ou de uso remoto) durante a demonstração ou a aula teórica.

- O laboratório não conta com a presença do aluno-monitor.

- O laboratório não se encontra aberto em horário conveniente.

- Não há previsão de provas práticas na disciplina.

- Não há critérios para a avaliação de estágio relacionados à habilidade manual.

- O aluno já tem experiência anterior na execução das técnicas.

- $\mathrm{O}$ aluno já teve experiências desagradáveis com um treinamento anterior semelhante.

- O aluno tem pouca necessidade pessoal de auto realização.

Das 45 respostas oferecidas, $19(42,2 \%)$ referem-se à responsabilidade do professor frente à desestimulação do estudante para treinar espontaneamente no L.E., $10(22,2 \%)$ referem-se às condições do L.E., 7 $(15,5 \%)$ à disciplina e $7(15,5 \%)$ ao próprio aluno.

Tentou-se analisar os mesmos dados de forma a comparar as respostas dos estudantes que não frequentaram (ou pouco frequentaram) o L.E. com as respostas daqueles que compareceram com maior frequência. Notou-se, entretanto, que não houve diferenças significativas entre estes dois grupos, nem nas respostas à questão aberta, nem nas respostas àquelas questōes que exigiam o auxílio de lista pré-elaborada.

Essa última tentativa de análise deveu-se à premissa de que essas diferenças poderiam explicar a diferença de comparecimento espontâneo dos estudantes ao treinamento no L.E. 


\section{CONCLUSOES}

O estudo em questão não é definitivo e apenas nos permitiu ter uma idéia dos fatores estimulantes e desestimulantes do treinamento espontâneo dos estudantes no L.E., na opinião de docentes e estudantes. A comprovaçãa experimental do efeito desses fatores deve ser objetivo) de trabalhos posteriores.

Verificou-se que o número de comparecimentos espontâneos dos estudantes ao L.E. varia de ano para ano. Enquanto os alunos de 1985 compareceram em média 7,8 vezes por estudante, em 1986 e 1987 essa mesma média caiu para 2,9 e 3,2 respectivamente.

Nas três turmas estudadas a segunda quinzena de março é a quinzena do $1^{\circ}$ semestre letivo com maior afluência de estudantes ao L.E. Esse pico, possivelmente, deve-se à curiosidade e ao entusiasmo provocados pelos primeiros contatos com as técnicas e com o próprio laboratório. Contudo, esse entusiasmo não se mantém por si só, havendo um significativo decréscimo do número de comparecimentos nas quinzenas seguintes. Em maio ou início de junho, o impacto causado pelos primeiros contatos com a realidade hospitalar e os pacientes internados, provavelmente explicam o pequeno recrudescimento que aparece nessa época nas três turmas.

O comparecimento dos estudantes deve-se ao fato deles pretenderem treinar as habilidades técnicas que exigem bastante destreza manual. Assim, verificou-se neste estudo que as técnicas mais procuradas são arrumação de cama, curativo, ataduras, colocação de luvas esterilizadas e cateterismo vesical. Dos 1615 treinamentos, 997 (61,7\%) são para treinar uma das cinco técnicas acima citadas.

Em relação à opinião de $15 \%$ ou mais de estudantes são condições que podem estimular o seu comparecimento espontâneo para treinamento no L.E.:

- A presença do professor ou do monitor no L.E.

Os estudantes parecem que sentem a necessidade de um "orientador" ou "facilitador". As técnicas de ensino em que o próprio aluno procura sua aprendizagem ainda não são muito conhecidas dos nossos estudantes. Reafirmaram essa opinião quando $15 \%$ ou mais também citaram a ausência do professor ou monitor como fator desestimulante. - A previsão de provas práticas na disciplina.

A cobrança da aprendizagem pelo professor é uma prática muito conhecida e esperada pelo aluno. Parece que o estudante só estudará se souber que lhe vão cobrar esse estudo uma vez que em toda sua vida escolar, possivelmente, foi o que aconteceu.

- Necessidade do estudante de sentir-se seguro junto ao cliente.

- Vontade do aluno de saber mais sobre as técnicas. 
Estes dois últimos itens parecem demonstrar que o estudante sabe que sua motivação pessoal é essencial para que compareça ao L.E. de forma espontânea para treinar as técnicas.

Assim, como a revisão bibliográfica deixa clara, são muito diferentes os conceitos de motivação e de estimulação. Os estudantes reforçaram a idéia de que, se cabe ao professor a responsabilidade de estimular, a motivação própria do estudante é condição imprescindivel. Quando tiveram a oportunidade de apontar os fatores desestimulantes $15 \%$ ou mais citaram "a falta de interesse do aluno pela prática" ou "a pouca necessidade de auto-realização do estudante".

Como fatores desestimulantes os alunos ( $15 \%$ ou mais) ainda acrescentaram as condições do próprio laboratório quando "o espaço físico é reduzido ou existe insuficiênciá de materiais em quantidade e qualidade frente à demanda de alunos".

$\mathrm{Na}$ opinião de $40 \%$ ou mais dos docentes, os fatores apontados como estimulantes são:

- Incentivo do professor ou monitor para o treinamento, entusiasmo por esse tipo de treinamento e elogios às habilidades bem treinadas.

Essa responsabilidede do professor foi reforçada quando $40 \%$ ou mais do docentes apontaram como fator desestimulante o "desinteresse e falta de entusiasmo do professor quando pouco se refere ao L.E. como recurso de aprendizagem ou não valoriza as técnicas que o aluno treinou".

- Presença do professor ou monitor no L.E. ou disponibilidade dos mesmos para auxiliar o estudante.

- Exigência e cobrança das técnicas pelo professor de estágio no campo.

- Previsão de provas práticas na disciplina.

Os docentes ( $40 \%$ ou mais) indicaram como fatores desestimulantes:

- O L.E. não se encontra em funcionamento (aberto) . .em horário conveniente ao aluno.

- O professor não define os objetivos de cada técnica com a determinação do número de vezes mínimo para treinamento.

- $O$ aluno não se interessa ou tem pouca necessidade de auto-realização.

Ao contrário do que aconteceu com os estudantes, os docentes atribuem ao professor a maior responsabilidade pela estimulação do estudante. Talvez saibam que a estimulação é a única forma de intensificar o comparecimento ao L.E., uma vez que a motivação é própria do estudante e o professor não tem como atuar nela, segundo alguns autores. Contudo, ao apontarem os fatores desestimulantes não deixaram de considerar o desinteresse do aluno como condição importante para o não comparecimento espontâneo. 
Frente a estas conclusões percebeu-se que inúmeros estudos experimentais poderão ser levados a efeito tomando cada uma destas condições como variável de estudo e aferindo o maior ou menor número de comparecimentos (ou o número de horas ou minutos) espontâneos ao L.E.

FRIEDLANDER, M.R.; LAGANA, M.T.C.; SILVEIRA, C.; SZOBO, M.A. Stimulis that help the pracitce in nursing laboratory: opinion of professors and students. Rev. Esc. Ent. USP, São Paulo, 24(1):41-65, Apr. 1990.

The authors developed a surveied on a population of 5 professors and 48 students on the reasons, that can to stimulate or to disfavour the voluntary attendance of the students to practice the psychomotor ability in the nursing laboratory. The results showed positive and negative reasons expected by professors and students to evaluate nursing laboratory training.

UNITERMS: Nursing education. Laboratory training.

\section{REFERENCIAS BIBLIOGRAFICAS}

AUSUBEL, D.P.; NOVAK, J.D.; haNBrian, H. Puicologia oducaclonal. 2. ed. Rlo do Janeiro, Interamericana. 1980.

CaArPOS, D.M. de S. Psioologie da aprondiragem. 16. ed. Petrópolis, Vczes, 1984.

FRImDLANDER, M.R.; SCHVARTZ, E.; TAVARBS, S.R. de A.G.B.; NOCA, C.R. da S. Frequancla dos estudantes ao laboratório de enfermagem como atividade de livre opclio. Rev. Gaúchw Ent. Porto Alegre, 8(2):183-201, Jul. 1984.

FRIEDLANDER, M.R. TANATA, C.8.; SIQUELRA, P.8. Hatímulos que Rrorecem o treinamanto no laboratório de enfermagem: revisăo de literatura. Bov. Bisc. Innt. USP, SEo Paulo, 2s(2) :116-25, ago. 1989.

NERICI, I.G. DIdation: uma introdugro. SGo Paulo, Atlas, 1981.

SLAVIN, R.E. Students motivating students to excel: cooperativa, Incentives, cooperative tesks and student achievement. The Elem. School J., Chicago, 85(1):63-63, 1984.

Recebido em 06/10/88 
ANEXO 1

CONTROLE DE TEMPO DE TREINAMENTO NO LABORATÓRIO DE ENFERMAGEM

Aluno:

Docente:

\begin{tabular}{l}
\hline Atividades \\
Sinais Vitais \\
\hline Peso e Altura \\
\hline Cama \\
\hline Limpeza de Unidade \\
Inalacão \\
\hline Medicaçäo DM \\
\hline Medicacăo EV + Coleta Sangue \\
\hline Soro \\
\hline Curativo \\
Banho \\
\hline Cateterismo Vesical \\
\hline Lavagem Intestinal \\
\hline Aplic. Quentes e Frias \\
\hline Exame Fisico \\
\hline Ataduras \\
\hline Higiene Oral \\
\hline Higiene e cuidado com olhos, \\
nariz e ouvidos \\
\hline Lavagem de Cabeça \\
\hline Ravagem Externa \\
\hline Outros \\
\hline
\end{tabular}




\section{ANEXO $\mathbf{I}$ \\ FORMULARIO PARA ENTREVISTA}

Nome:

Idade:

Data da entrev.

Aluno: Ano que cursou Fund. de Enf.

Numero de vezes que usou o L.E.

Professor:

Lecionou Fund. de Enf. am 85, 86, 87:

A) Condiçoes que estimulam o aluno a frequentar o L.E. espontaneamente:

1) Resposta aberta:

2) Resposta com auxilio da lista:

B) Condigoes que desestimulam o aluno a frequentar o L.J. espontaneamente. Resposta aberta:

4) Resposta com auxillo do lista:

NOTA: Em caso de necessidade usar o verso da folha. 


\section{ANEXO III}

\section{LISTA 1}

Candigres que podem estimular o estudante a treinar as habilidades peicomotoras no laboratório de enfermagem (L.E.) como atividade de livre opgăo.

Orientagão: Escolha, dentre as 27 opçðes existentes, as 10 que voce achar mais importantes para estimular o estudante.

1. O professor mostra de forma clara e preciso os objetivos do treinamento de cąda uma das técnicas.

2. O professor demanstra entusiasmo pelo treinamento dos alunos no L.E.

3. O professor elogia com frequéncia as habilidades bem treinadas.

4. O professor mostra explicitamente ao estucante aquelas habilidades que ele não executa bem e que deveriam ser melhor treinadas.

5. O professor está disporível quando o estudante precisa de auxillio para treinar no L.E.

6. A técnica parece complexa durante a aula tebrica ou a demonstração.

7. A técnica já era conhecida do aluno (visto alguém fazer ou ouvido alguém falar) antes de começar a disciplina Fund. de Enf.

8. A técnica já fol necessária ao aluno (para atender alguém da familia ou colega) que não a executou por não corhec ŝ-la.

9. O laboratório conta com espaço físico, claricade e boa disposição do equipamento.

10. O laboratório conta com a presença do aluno-monitor.

11. O laboratório conta com a presença do professor.

12. O laboratório conta com material e equipamento suficientes em quantidade $\theta$ qualidade.

13. O laboratório encontra-se aberto em horário conveniente.

14. O laboratório conta com várias formas de treinamento (treinamento em manequins, em colegas e roteiros auto-instrucionais).

15. O campo de estágio usado pela disciplina é muito rico em oportunidades.

16. O professor de estágio é muito exigente e cobra muito.

17. Previsão de provas práticas em Fund. de Enf.

18. Previsão de proves teóricas que podem conter questðes práticas.

19. O estágio ser avaliaco por meio de critérios que considerem as habilidades manuais.

20. O aluno tem medo de errar junto ao paciente.

21. O aluno quex ser um profissional reconhecido por seus pacientes, por seus colegas a por outros profissionais.

22. O aluno quer ser respeitado em seu ambiente escolar.

23. O aluno quer obter sucesso nos estudos e ser considorado pela família, professores, amigos e colegas.

24. O aluno quer saber bem as técnicas porque gosta cas habilidades manuais.

25. O aluno é uma pessoa curiosa

26. O aluno quer formar-se o mais rápido possivel para trabalhar e ganhar o proprio sustento.

27. O aluno quer ficar livre de compromisso assumido consigo próprio para poder realizar outra atividade.

Rev. Esc. Enf. USP, Săo Paulo, 24(1) :41-65, abr. 1990 


\section{ANEXO IV}

\section{LISTA 2}

Condicões que podem desestimular o estudante a treinar as habilidades psicomotoras no laboratório de enfermagem (L.E.) como atividade de livre opgáo.

Orientação: Escclha, dentre as 22 opções existertes, as 10 que você achar mais importantes para diminuir o estímulo do estudante.

1. O professor não define os objetivos do treinamento de cada uma das técnicas com clareza.

2. O professor quase não se refere ao treinamento no L.E. como recurso de aprendizagem.

3. O professor não valorizar as técnicas que o aluno treinou.

4. O professor nāo tem disponibilidade quando o aluno the per.e auxílio para treinar no L.E.

5. O professor salienta a facilidade cois que a técnica pode ser executada durante as aules teóricas.

6. As tćcnicas parecem muito fáceis ao serem demonstradas.

7. As técnicas parecem pouco úteis (ou de uso pouco comum ou de uso remoto) durante a demonstração ou a aula teórica.

8. O laboratório conta com pouco espaço físico, pouca claridade ou com uma disposição do material pouco conveniente.

9. O laboratório não conta com a presença do monitor.

10. O laboratorio não conta com a presença de um professor.

11. O laboratório não se encontra aberto em horário conveniente.

12. O laboratório não conta com equipamento e material suficiente em quantidade e qualidade.

13. O campo de estágio usado pela disciplina e pobre em número de oportunidades para execução de técnicas.

14. O professor de estágio não exige muito em relação à perfeição da execução das técnicas.

15. Nâo estão previstas provas práticas na disciplina.

16. Não haverem critérios para avaliação de est́́gio relacionados à habilidade manual.

17. O professor ou monitor transmitiren muita ansiedade ao estudante durante o - treinamerto no L.E.

18. O aluno ser muito ncrvoso.

19. O aluno já ter experiência anterior nas técnicas.

20. O aluno ter duficuldade excessiva na execuৎ̧̃o de atividades manuais.

21. O aluno já ter tido experiências desagradáveis com um treinamento anterior no L.E.

Recebido em 06/10/88 